\title{
SILVER/ALUMINA CORE/SHELL NANOPATTERNED FILMS FOR IN-FIELD DETECTION OF SOIL AND WATER PHOSPHORUS USING SURFACE ENHANCED RAMAN SPECTROSCOPY
}

\author{
1,2Jan PRÁŠEK, ${ }^{1,2}$ Radim HRDÝ, ${ }^{3}$ Dušan HEMZAL, ${ }^{1,2}$ Jana DRBOHLAVOVÁ, ${ }^{4}$ Radovan KOPP \\ ${ }^{1}$ CEITEC, Brno University of Technology, Brno, Czech Republic, EU, prasek@vutbr.cz, \\ jana.drbohlavova@ceitec.vutbr.cz
}

${ }^{2}$ Faculty of Electrical Engineering, Brno University of Technology, Brno, Czech Republic, EU, hrdy@vutbr.cz,

${ }^{3}$ Faculty of Science, Masaryk University, Brno, Czech Republic, EU, hemzal@physics.muni.cz

${ }^{4}$ Faculty of Agronomy, Mendel University, Brno, Czech Republic, EU, radovan.kopp@mendelu.cz

https://doi.org/10.37904/nanocon.2021.4338

\begin{abstract}
In this paper, results of our running work on a sensitive and efficient detection of phosphates are presented. We develop a testing kit for rapid chemical detection based on surface-enhanced Raman scattering (SERS). We combine highly SERS active silver layer with a thin overlayer of alumina that is able to adsorb phosphorus compounds, in the form of silver/alumina core/shell nanopatterned film. In the first step, the silver layer was prepared by physical vapor deposition, followed by thermal annealing to form silver nanodots. Subsequently, alumina film was deposited over the silver nanodots using atomic layer deposition to form the silver/alumina core/shell nanopatterned surface. The prepared $\mathrm{Ag} / \mathrm{Al}_{2} \mathrm{O}_{3}$ films can vary in overall thickness from 4 to $10 \mathrm{~nm}$ by changing the deposition parameters. The produced $\mathrm{Ag} / \mathrm{Al}_{2} \mathrm{O}_{3}$ nanodots exhibit high SERS activity and significant adsorption of phosphate anions on these nanofilms has been confirmed under $532 \mathrm{~nm}$ excitation, which produced characteristic phosphate bands in the Raman spectra. The method will be further applied for quantitative detection of inorganic phosphates as well as organophosphates in real pond water samples.
\end{abstract}

Keywords: Phosphorus, phosphate, detection, core/shell, nanoparticles, Raman spectroscopy, SERS

\section{INTRODUCTION}

Water quality is likely to be one of the main limiting factors for the Central European pond industry in the future [1]. Understanding and timely assessment of chemical balance in the composition of aquatic ecosystems, namely in ponds and lakes, can prevent heavy economic losses in fish production. The phosphorus concentration plays a key role in the development of the phytoplankton community as it is influencing the basic physicochemical parameters in water. A sufficient concentration of dissolved oxygen in the water is a crucial parameter for the survival of fish in ponds. Rapid detection of changes in the phosphate compounds concentration in water, organic sediments, and pond soil, is therefore very important.

Phosphorus is a biogenic element that has a major influence on the primary production of green plants. Phytoplankton can utilise not only phosphorus from orthophosphate but also orthophosphate absorbed on the surface of suspended solids. Sorption and desorption processes of phosphate in sediments thus play an important role in changes of phosphorus concentration [2]. On contrary to lakes and reservoirs, not only the residence time of water in ponds but also the trophic level, sediment quality, and the intensity of pond management are crucial for phosphorus cycling [3]. Estimating nutrient retention in ponds using simple models is therefore not realistic and highly accurate field data measured in an appropriate way are urgently needed.

One of the techniques suitable for in-field analysis of phosphorus compounds in water and water sediment (soil) in real environmental conditions is Raman spectroscopy, as it offers a measurement using a portable 
device [4]. The advantage of this analytic tool is that water does not generally interfere with Raman spectral analysis. However, the technique needs to be sensitive enough to qualitatively as well as quantitatively distinguish among various types of phosphates. Surface-enhanced Raman scattering (SERS) might provide such an improvement of sensitivity, but so far, there is only minimum scientific evidence for this application in phosphate analysis [5].

In this paper, we report on the design and development of testing kit based on SERS for rapid and precise detection of phosphate compounds dissolved in pond water. The testing kit is developed as a core-shell nanopatterned surface formed by silver nanodots to enhance the Raman signals and ultra-thin alumina layer to bind the free phosphate from the tested sample. While silver is well known as one of the excellent candidates for enhancing the signal of Raman scattering, alumina in combination with silver was used for SERS so far only rarely [6]. For instance, the deposition of alumina on $\mathrm{Ag}$ to create a hybrid SERS platform has been previously reported for spectroscopic detection of water splitting reaction intermediates, where a thin layer of alumina helped to prevent charge transfer between $\mathrm{Ag}$ and the reaction system [7]. In another case, nanoporous alumina served as a template for the subsequent deposition of silver nanoparticles to be used in SERS [8]. Oliveira et al. found that $\mathrm{Al}_{2} \mathrm{O}_{3}$ seems to be the most suitable material for removing phosphate from aquatic systems with eutrophication problems [9]. The reason is that alumina has a very high surface area, is insoluble in water and is selective for $P$ in the presence of chloride and sulphate ions.

According to the literature, our $\mathrm{Ag} / \mathrm{Al}_{2} \mathrm{O}_{3}$ nanopatterned system, where alumina facilitates phosphate scavenging [10] and simultaneously enables oxidative protection of core silver, is the first one to be used for the direct phosphate SERS analysis in a pond aquatic environment. The objective of our study was to verify a suitability of chosen materials and the methods for our samples' fabrication for their subsequent application in SERS analysis of phosphate.

\section{EXPERIMENTAL}

\subsection{Testing kit fabrication}

Two types of testing kit were developed: the first type was fabricated on a silicon substrate: $8 \mathrm{~nm} \mathrm{Ag} \mathrm{dots}$ covered with $2 \mathrm{~nm}$ of $\mathrm{Al}_{2} \mathrm{O}_{3}$ and pure $8 \mathrm{~nm} \mathrm{Ag}$ dots for reference. In particular, the $15 \times 15 \mathrm{~mm}$ substrates were cut from 5" p-type Si wafers (Siegert Wafer GmbH, Germany) of crystallographic orientation (100), thickness $\approx 525 \mu \mathrm{m}$, and specific resistivity $<5 \mathrm{~m} \Omega \cdot \mathrm{cm}$. The silver (99.99\% pure, Kurt J. Lesker, USA) film was deposited using e-beam thermal evaporation (Bestec, Germany), while its thickness was monitored during the deposition using calibrated quartz crystal microbalance. Subsequently, the $2 \mathrm{~nm}$ thick alumina layer was deposited using Atomic layer deposition (ALD) from trimethylaluminum precursor (99.999+\% pure, PURATREM-High Purity Inorganic, Strem, USA) using Fiji 200 ALD deposition system (Ultratech/CambridgeNanoTech/Veeco, USA). Before the ALD process, the substrate with Ag film was inserted to the process chamber and annealed at $300^{\circ} \mathrm{C}$ for 15 minutes to create the nanodot structure and to remove the water residues from the surface. The $2 \mathrm{~nm}$ thick $\mathrm{Al}_{2} \mathrm{O}_{3}$ film was deposited in 20 cycles with the thickness of $1 \AA$ per cycle at $300{ }^{\circ} \mathrm{C}$. The $\mathrm{O}_{2}$ plasma was used to enhance the deposition.

The second type of testing kit was fabricated on a sapphire substrate. The sapphire was chosen just as a comparative material to verify if silicon does not interfere with phosphates in Raman measurement via false positive signals. The $15 \times 15 \mathrm{~mm}$ substrates were cut from C-plane orientation (0001) sapphire wafers (Siegert Wafer $\mathrm{GmbH}$, Germany) with diameter of $\approx 100 \mathrm{~mm}$, thickness of $\approx 650 \mu \mathrm{m}$, and $99.998 \%$ purity. The silver film of $10 \mathrm{~nm}$ thickness was deposited using e-beam thermal evaporation; the Ag thickness was monitored by calibrated quartz crystal microbalance method during the deposition process. The $2 \mathrm{~nm}$ thick alumina layer was deposited using the same ALD process as described above, with annealing and deposition temperatures set to $300^{\circ} \mathrm{C}$. 


\subsection{Morphology analysis of $\mathrm{Ag} / \mathrm{Al}_{2} \mathrm{O}_{3}$ core/shell nanopatterned film}

The surface morphology and homogeneity of the fabricated samples were investigated with field scanning electronic microscope (MIRA-II LMU, Tescan, Czech Republic) operated at 1-30 keV in high vacuum mode. Images were captured under $15 \mathrm{kV}$ using InBeam or standard SE detector.

\subsection{Raman measurements}

To check the basic SERS activity of the prepared kits, the Si/Ag and Si/Ag/Al $\mathrm{O}_{3}$ nanopatterned substrates have been used in combination with an organic dye; providing several additional orders of resonant enhancement, the SERRS spectra of organic dyes allow for sensitive quantification of SERS activity of the substrates.

In particular, $3 \mu \mathrm{L}$ droplets of $1 \mu \mathrm{M}$ aqueous solution of (brilliant) cresyl blue (Sigma-Aldrich) were cast on the substrates and let dry. The subsequent Raman characterization has been accomplished using $532 \mathrm{~nm}$ diodepumped solid-state (DPSS) laser with nominal power of $10 \mathrm{~mW}$ and $\times 20$ objective with $N A=0.4$. By stretching the laser spot into a line, the StreamLine ${ }^{\mathrm{TM}}$ modality of the used Renishaw inVia spectrometer allows to combine low sample heating with shortened acquisition time thanks to parallelized accumulation scheme. In our case, the resulting power in the spot of measurement was about $250 \mu \mathrm{W}$ and the Raman maps with resolution around $100 \times 100$ pixels over an area of about $3 \times 3 \mathrm{~mm}$ with $1 \mathrm{~s}$ accumulation at each pixel were measured in about 6 min overall accumulation time. The obtained Raman maps overcome single-point measurements by detailed information on SERS activity distribution over the sample and allow to safely evaluate the mean SERS enhancement of the substrates.

The ability of sapphire-based $\mathrm{Ag} / \mathrm{Al}_{2} \mathrm{O}_{3}$ nanopatterned film to detect the phosphate was tested with $10 \mathrm{mM}$ $\mathrm{K}_{3} \mathrm{PO}_{4}$ (Sigma-Aldrich) aqueous solution prepared from high purity $(>18 \mathrm{M} \Omega . \mathrm{cm})$ demineralized water (DI). The kits were immersed in the phosphate solution for $30 \mathrm{~min}$ and let dry on air. Consequently, Raman maps were taken under conditions similar to Si-based substrates measurement described above.

\section{RESULTS AND DISCUSSION}

\subsection{SEM analysis of silver/alumina core/shell nanodots}
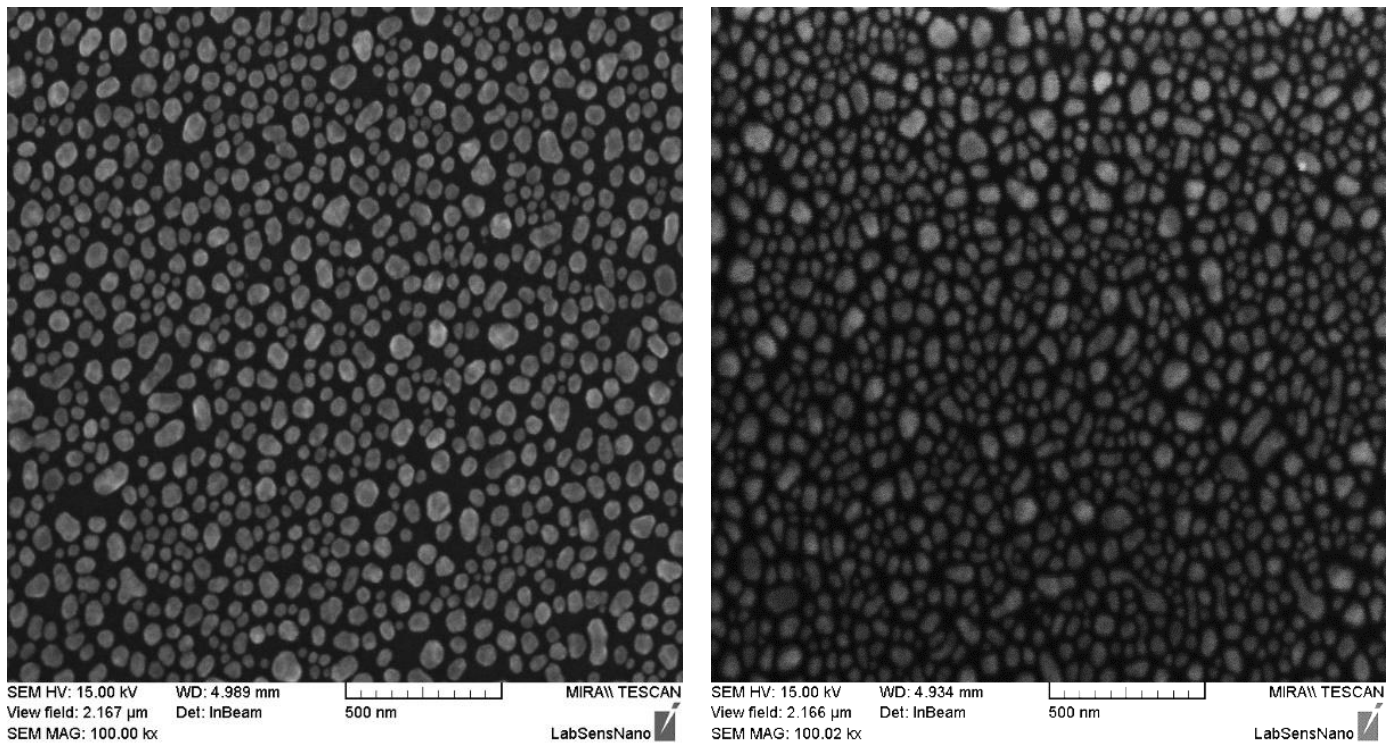

Figure 1 The SEM comparison of $8 \mathrm{~nm}$ thick silver nanodots without (left) and with (right) alumina shell prepared on silicon substrate using ALD fabrication process at $300{ }^{\circ} \mathrm{C}$. 
The testing kits with core/shell structures were successfully fabricated using the thermal e-beam evaporation and ALD techniques on the silicon substrate as mentioned in chapter 2 and investigated using scanning electron microscopy (SEM). The comparison of $8 \mathrm{~nm}$ thick silver nanodots without (left) and with (right) alumina shell prepared on the silicon substrate using ALD fabrication process at $300^{\circ} \mathrm{C}$ are shown in Figure 1. From the comparison is clear that there is no significant change in the structure after the alumina shell deposition. The success deposition can be deducted from worse focus which is given by worse charge transfer from the sample covered with non-conductive alumina shell.

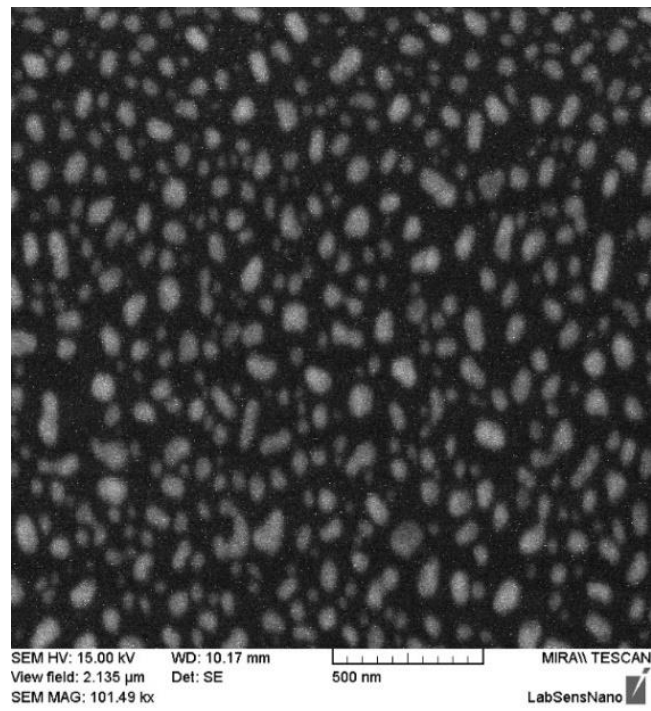

Figure 2 The $10 \mathrm{~nm}$ thick silver/alumina core/shell nanodots prepared on sapphire substrate by ALD fabrication process at $300^{\circ} \mathrm{C}$.

Figure 2 shows the $10 \mathrm{~nm}$ thick silver/alumina core/shell nanodots prepared on sapphire substrate by ALD fabrication process at $300{ }^{\circ} \mathrm{C}$. In comparison with the samples fabricated on the silicon substrate the structure on sapphire substrate resulted in less dense structure which is probably given by the initial silver layer thickness.

\subsection{SERS activity of $\mathrm{Ag} / \mathrm{Al}_{2} \mathrm{O}_{3}$ nanopatterned substrates}
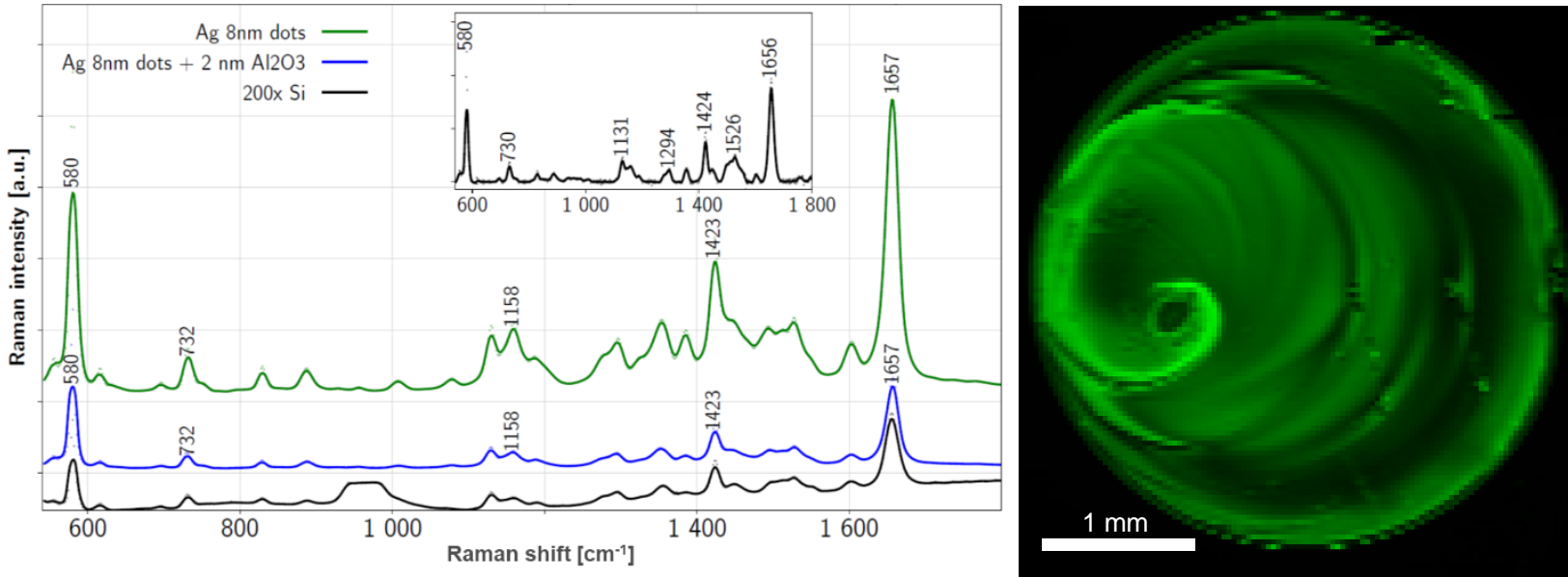

Figure 3 Background-corrected Raman spectra cumulated over the whole area of dried $3 \mu \mathrm{L}$ droplets of $1 \mu \mathrm{M}$ cresyl blue over Si based substrates (left panel); the inset shows spectrum of $100 \mathrm{mM}$ aqueous cresyl blue solution for comparison. Distribution of the analyte across the dried droplet is shown in the right panel using $1657 \mathrm{~cm}^{-1}$ peak intensity mapping. 
The Raman maps for dried droplets on Si-based substrates were taken with both $\mathrm{Ag}$ nanodots and $\mathrm{Ag} / \mathrm{Al}_{2} \mathrm{O}_{3}$ nanopatterned film; the resulting cumulated Raman spectra are shown in Figure 3. Performing the measurement over the whole dried droplets, the overall SERS enhancement can be safely evaluated despite nonhomogeneous droplet coverage (cf. Figure 3). In particular, the SERS enhancement of the nanopatterned $\mathrm{Si} / \mathrm{Ag}$ surface was found close to $10^{3}$ (prior to its calculation, all spectra were corrected for a pure $\mathrm{Si}$ background). Although SERS enhancement for $\mathrm{Ag} / \mathrm{Al}_{2} \mathrm{O}_{3}$ nanopatterned film is smaller than for $\mathrm{Ag}$ nanodots, alumina serves as both $\mathrm{Ag}$ capping agent to prevent aging of the pure silver surface due to its oxidation and scavenger of phosphate from the tested solution. The decrease of SERS enhancement to about 200x for $\mathrm{Ag} / \mathrm{Al}_{2} \mathrm{O}_{3}$ nanopatterned film thus seems a reasonable compromise for efficient phosphate analysis.

\subsection{Phosphate detection using $\mathrm{Ag} / \mathrm{Al}_{2} \mathrm{O}_{3}$ nanopatterned substrates}

To test the response of the kits towards phosphates, sapphire-based substrates were used together with $10 \mathrm{mM}$ aqueous solution of $\mathrm{K}_{3} \mathrm{PO}_{4}$ as a model testing analyte; the concentration is comparable with expected range of phosphate abundance in the real pond water samples. The SERS results after soaking the substrates into the $\mathrm{K}_{3} \mathrm{PO}_{4}$ solution for 30 min are shown in Figure 4. The SERS spectra have been accumulated from an area about $100 \times 100 \mu \mathrm{m}$ under the collection conditions like measurement with the cresyl blue described above.

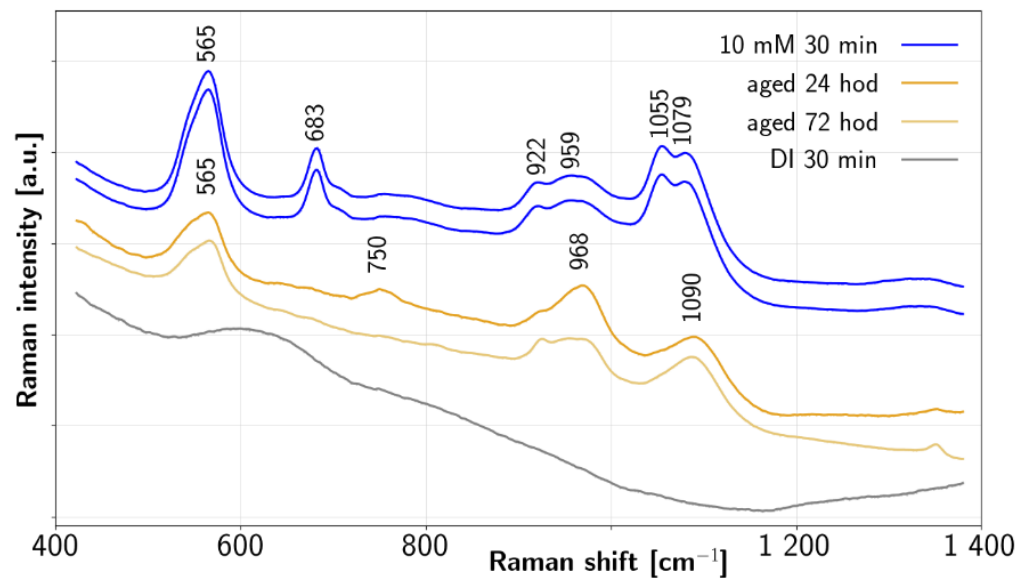

Figure 4 Cumulated Raman spectra $(5 \mathrm{~mW}$ at $532 \mathrm{~nm}, 368 \mathrm{~s})$ after soaking the sapphire $/ \mathrm{Ag} / \mathrm{Al}_{2} \mathrm{O}_{3}$ substrates into $10 \mathrm{mM} \mathrm{K}_{3} \mathrm{PO}_{4}$ solution for $30 \mathrm{~min}$. To track the stability, the sample was measured also one and three days after deposition of the phosphate. In addition, the spectrum resulting from soaking the sapphire/Ag/ $/ \mathrm{Al}_{2} \mathrm{O}_{3}$ substrates in water $(\mathrm{DI})$ is shown.

The spectra show a combination of characteristic phosphate bands [11]: $\mathrm{K}_{3} \mathrm{PO}_{4}$ peak at $922 \mathrm{~cm}^{-1}$ (solid), $\mathrm{H}_{2} \mathrm{PO}^{4-}$ peak at $1074 \mathrm{~cm}^{-1}$ (liquid), and a broad band for other phosphate ions in aqueous solution $\left(989 \mathrm{~cm}^{-1}\right.$ for $\mathrm{HPO}_{4}^{2}, 934 \mathrm{~cm}^{-1}$ for $\mathrm{PO}_{4}^{3-}$ ). For comparison, Figure 4 also shows the spectrum after soaking the substrate to pure water, proving that the observed peaks are justly assigned to the tested phosphate analyte. The SERS spectra re-measured 1 and 3 days after the phosphate deposition show that alumina shell deposited over silver ensured a sufficient stability of prepared SERS surface. This proves that our silver/alumina samples have a high potential in direct and reproducible analysis of phosphates.

\section{CONCLUSION}

The silver/alumina core/shell on substrates for SERS detection of phosphate in aqueous solution were successfully prepared and tested in detection of phosphates in the range of interest. The SERS activity was increased after the silver deposition about 1000 times. Although the intensity of Raman signal enhancement decreased after alumina deposition, the sample still allows the detection of phosphate in aqueous solution with sufficiently strong signal. In future research, we suggest optimizing alumina layer for better enhancement of 
Raman signal and for selective scavenging of different phosphates from the real pond solutions. In addition, the presented testing kits should be optimized not only to qualitative but also quantitative detection of phosphates and organophosphates in water and water sediments.

\section{ACKNOWLEDGEMENTS}

This study was supported by a research project funded by the National Agency for Agricultural Research (QK1810161). The work was also carried out with the support of CzechNanoLab Research Infrastructure supported by MEYS CR (LM2018110).

\section{REFERENCES}

[1] WEZEL, A., ROBIN, J., GUERIN, M., ARTHAUD, F.VALLOD, D. Management effects on water quality, sediments and fish production in extensive fish ponds in the Dombes region, France. Limnologica, 2013, vol. 43, pp. 210218.

[2] BOROVEC, J., HEJZLAR, J.VYHNALEK, V. Phosphorus cycling in a dimictic reservoir - the Sec Reservoir (Czech Republic). International Review of Hydrobiology. 1998, vol. 83, pp. 295-302.

[3] HEJZLAR, J., ŠÁMALOVÁ, K., BOERS, P.KRONVANG, B. Modelling Phosphorus Retention in Lakes and Reservoirs. Water, Air, \& Soil Pollution: Focus. 2006, vol. 6, pp. 487-494.

[4] KRUSE, J., ABRAHAM, M., AMELUNG, W., BAUM, C., BOL, R., KUHN, O., LEWANDOWSKI, H., NIEDERBERGER, J., OELMANN, Y., RUGER, C., SANTNER, J., SIEBERS, M., SIEBERS, N., SPOHN, M., VESTERGREN, J., VOGTS, A.LEINWEBER, P. Innovative methods in soil phosphorus research: A review. Journal of Plant Nutrition and Soil Science. 2015, vol. 178, pp. 43-88.

[5] JI, W., SONG, W., TANABE, I., WANG, Y., ZHAO, B.OZAKI, Y.H. Semiconductor-enhanced Raman scattering for highly robust SERS sensing: the case of phosphate analysis. Chemical Communications. 2015, vol. 51, pp. 76417644.

[6] YANG, P.S., YIN, Y.T., LIN, P.C., CHEN, L.Y.CHEN, M.J. High chemical resistance and Raman enhancement in $\mathrm{Ag} / \mathrm{Al} 2 \mathrm{O} 3$ core-shell plasmonic nanostructures tailored by atomic layer deposition. Materials Chemistry and Physics. 2019, vol. 223, pp. 441-446.

[7] LING, X.Y., YAN, R.X., LO, S., HOANG, D.T., LIU, C., FARDY, M.A., KHAN, S.B., ASIRI, A.M., BAWAKED, S.M.YANG, P.D. Alumina-coated Ag nanocrystal monolayers as surfaceenhanced Raman spectroscopy platforms for the direct spectroscopic detection of water splitting reaction intermediates. Nano Research. 2014, vol. 7, pp. 132-143.

[8] LU, Z., RUAN, W., YANG, J., XU, W., ZHAO, C.ZHAO, B. Deposition of Ag nanoparticles on porous anodic alumina for surface enhanced Raman scattering substrate. Journal of Raman Spectroscopy. 2009, vol. 40, pp. 112-116.

[9] OLIVEIRA, M., RIBEIRO, D., NOBREGA, J.M., MACHADO, A.V., BRITO, A.G.NOGUEIRA, R. Removal of phosphorus from water using active barriers: Al2O3 immobilized on to polyolefins. Environmental Technology. 2011, vol. 32, pp. 989-995.

[10] HUANG, C.P.STUMM, W. Specific adsorption of cations on hydrous Y-Al2O3. Journal of Colloid and Interface Science. 1973, vol. 43, pp. 409-420.

[11] RUDOLPH, W.W. Raman- and infrared-spectroscopic investigations of dilute aqueous phosphoric acid solutions. Dalton Transactions. 2010, vol. 39, pp. 9642-9653. 